OPEN ACCESS

Edited by:

Beat Knechtle,

Universitätsklinikum Zurich,

Switzerland

Reviewed by:

Josef Klhùfek

Tomas Bata Regional Hospital,

Czechia

Abu Saleh Md Moin

Qatar Foundation, Qatar

Sandeep Surendra Panikar,

Washington University Medical

Center, United States

Tiantian Yan,

990th Hospital of the People's

Liberation Army, China

Markov Georgievich Alexander,

Saint Petersburg State University,

Russia

*Correspondence:

Hamid Arazi

hamidarazi@yahoo.com

Specialty section:

This article was submitted to

Exercise Physiology,

a section of the journal

Frontiers in Physiology

Received: 25 July 2021 Accepted: 11 October 2021 Published: 15 November 2021

Citation:

Arazi H, Falahati $A$ and Suzuki K (2021) Moderate Intensity Aerobic Exercise Potential Favorable Effect

Against COVID-19: The Role

of Renin-Angiotensin System

and Immunomodulatory Effects.

Front. Physiol. 12:747200

doi: 10.3389/fphys.2021.747200

\section{Moderate Intensity Aerobic Exercise Potential Favorable Effect Against COVID-19: The Role of Renin-Angiotensin System and Immunomodulatory Effects}

\author{
Hamid Arazi ${ }^{1 *}$, Akram Falahati ${ }^{1}$ and Katsuhiko Suzuki ${ }^{2}$ \\ ${ }^{1}$ Department of Exercise Physiology, Faculty of Sport Sciences, University of Guilan, Rasht, Iran, ${ }^{2}$ Faculty of Sport Sciences, \\ Waseda University, Tokorozawa, Japan
}

The coronavirus disease (COVID-19) pandemic is caused by a novel coronavirus (CoV) named severe acute respiratory syndrome coronavirus 2 (SARS-CoV-2). As the angiotensin converting enzyme 2 (ACE2) is the cellular receptor of SARS-CoV-2, it has a strong interaction with the renin angiotensin system (RAS). Experimental studies have shown that the higher levels of ACE2 or increasing ACE2/ACE1 ratio improve COVID19 outcomes through lowering inflammation and death. Aerobic moderate intensity physical exercise fights off infections by two mechanisms, the inhibition of ACE/Ang II/AT1-R pathway and the stimulation of ACE2/Ang-(1-7)/MasR axis. Exercise can also activate the anti-inflammatory response so that it can be a potential therapeutic strategy against COVID-19. Here, we summarize and focus the relation among COVID-19, RAS, and immune system and describe the potential effect of aerobic moderate intensity physical exercise against CoV as a useful complementary tool for providing immune protection against SARS-CoV-2 virus infection, which is a novel intervention that requires further investigation.

Keywords: renin angiotensin system, SARS-CoV-2, coronavirus, inflammation, immune protection

\section{INTRODUCTION}

Severe acute respiratory syndrome coronavirus 2 (SARS-CoV-2) is the virus that leads to coronavirus disease (COVID-19), which is a novel beta-coronavirus pandemic. The angiotensin converting enzyme 2 (ACE2) is the cellular receptor of SARS-CoV-2 (Chen et al., 2020). ACE is a key regulator of the renin-angiotensin system (RAS). Components of RAS include angiotensinogen (ANG), angiotensin I (Ang I), Ang II, renin, and the ACE (Banu et al., 2020). ACE1 and its homolog ACE2 are the two antagonistic enzymes of the RAS, which balance and offset each other (Tipnis et al., 2000). ACE1 is a key hormonal system that transforms Ang I to Ang II, starting with renin mediating the transformation of ANG to Ang I (Rigat et al., 1990), which induces complicated processes including vasoconstriction, inflammation, and fibrosis through the Ang II type 1 receptor (AT1-R) (Gemmati et al., 2020). 
Contrarily, ACE2 basically leads to a cascade of enzymatic reactions eventuating in the creation of Ang 1-7, by conversion of Ang-II to Ang 1-7 and binding to Mas-related G-protein receptor (Tipnis et al., 2000; Burrell et al., 2004; Ocaranza and Jalil, 2012), which transduces the vasodilator, anticoagulant, anti-inflammatory, anti-fibrosis, and anti-oxidative activities, protecting the organs and blood vessels by counteracting the effects of Ang-II (Gemmati et al., 2020). In addition, angiotensin receptor type 2 (AT2R) also has anti-inflammatory and antifibrosis effects (Figure 1).

A negative correlation between ACE2 molecular levels and SARS-CoV-2 fatality has been confirmed (Chen et al., 2020). Physical Exercise (PE) interacts with RAS, one of the most critical pathways in COVID-19, by suppressing or downregulating ACE1 and AT1-R (Evangelista, 2020). As it was stated before, ACE2 is the receptor of SARS-CoV-2. Also PE leads to the higher ACE2, the distinction being that ACE2 pathway provoked by $\mathrm{PE}$ increases circulating levels of Ang (1-7) by the activation of ACE2/Ang 1-7/Mas- $\mathrm{R}$ axis, which induces an anti-inflammatory and anti-fibrotic effect (Nunes-Silva et al., 2017), but after the initial entry of SARS-CoV-2 through ACE2, consecutive downregulation of ACE2 expression happens, which results in an imbalance between Ang II/Ang 1-7 ratio and exacerbating inflammatory response (Vaduganathan et al., 2020). In fact, SARS-CoV-2 spike protein downregulates ACE2 leading to an overactivated Ang II/AT1R axis, and the detrimental consequences of Ang II may reveal the multiorgan disorders (Banu et al., 2020).

The effects of PE on the RAS are consistent with benefit of RAS inhibitor treatment in COVID-19 infection, which might

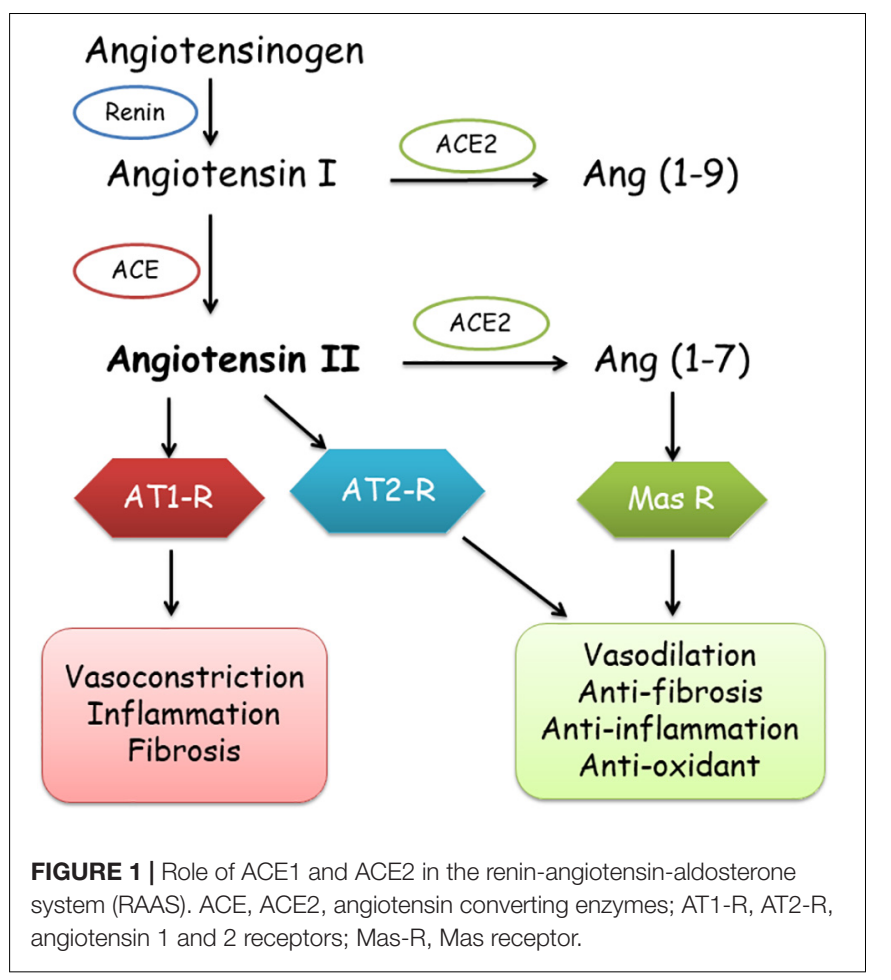

be potentially economic and effective in lowering the severity of clinical outcome (Evangelista, 2020). Therefore, exercise has been argued as a probable therapeutic strategy against COVID-19 via effects on ACE2 (Heffernan and Jae, 2020).

The other critical feature of COVID-19 is the inflammatory response, which occurs in two stages. The first is during the incubation phase of the disease, in which innate immune responses are generated, which can enhance the immune system to resist the virus (Shi et al., 2020). Mild symptoms like fever and cough are probable in this stage. Severe manifestations do not appear in the incubation phase (Zbinden-Foncea et al., 2020).

The second stage of the disease becomes severe in case the patient's innate immune system is not able to defeat the virus (Shi et al., 2020), and thus the adaptive immune system initiates. Over this second phase, pro-inflammatory cytokines [i.e., interleukin (IL)-2, IL-7, IL-10, granulocyte colony-stimulating factor (GCSF), interferon gamma-induced protein 10 (IP-10), monocyte chemoattractant protein-1 (MCP-1), macrophage inflammatory proteins-1alpha (MIP-1A), and tumor necrosis factor-alpha (TNF)- $\alpha$ ] increase significantly in the blood flow, which is called cytokine storms (Mehta et al., 2020), along with classic symptoms such as fever, cough, fibrosis, and on top of all these, lung inflammation as the major cause of lethal respiratory disorder (Zbinden-Foncea et al., 2020). In individuals with defective immune system, the virus will wipe out concerned cells, especially in tissues with large expression of ACE2 (Zbinden-Foncea et al., 2020).

The progression of COVID-19 symptoms depends heavily on the basic health condition of the person and the immune response provoked by the infection (Shi et al., 2020). The severity of COVID-19 is largely linked with host factors, chiefly cellular immune responses in patients (Zhou and Ye, 2021). Patients with mild COVID-19 and improved patients with severe COVID-19 exhibit a normal immune response to effectively exclude the virus and lastly recover to the preinfection stage (Zhou and Ye, 2021).

A definite adaptive immune response is needed to cease disease progression, and defeat the virus; so interventional approach like exercise to improve anti-inflammatory or constrict pro-inflammatory response should be mainly argued (ZbindenFoncea et al., 2020). Suppression of IL-1 and IL- 6 has been shown to have a therapeutic effect in many inflammatory diseases, including viral infections (Shi et al., 2020). Muscle-derived IL6 does not act as an inflammatory cytokine, but rather as an anti-inflammatory myokine.

It is safe to exercise during the COVID-19 pandemic for healthy individuals. Active lifestyle boosts the immune function while inactivity suppresses it (Suzuki, 2019). Accordingly, it is of prime importance to stay as active as possible during COVID19 quarantine period. Some researchers believe that intensity is the only important variable but others have claimed that the influence of training volume, intensity, frequency, exercise selection, exercise variety, sets, reps, rest, and tempo are equally important (Wang et al., 2020).

High intensity exercise (HIE) impairs immune function, which is called "open window" theory; hence, because of originating oxidants and suppression of immune system may be threatening and help to aggravate the COVID-19 
disease (Rahmati-Ahmadabad and Hosseini, 2020). Some people infected with the coronavirus $(\mathrm{CoV})$ do not reveal any symptoms for several days; accordingly, HIE should be avoided or applied with caution during the novel coronavirus (2019-nCoV) quarantine period (Rahmati-Ahmadabad and Hosseini, 2020).

It is suggested to use moderate intensity exercise as a nonpharmacological, cheap, and applicable approach to deal with COVID-19 virus (Rahmati-Ahmadabad and Hosseini, 2020).

So, we hypothesized that aerobic moderate intensity exercise may be considered as an adjuvant strategy for increasing ACE2/ACE1 ratio and boosting anti-inflammatory function and as a result decrease severity of COVID-19.

The novel demonstration of the ACE2 enzyme receptor as the main factor of cellular entry by the SARS-CoV-2 and different anti-inflammatory pathways of moderate intensity exercise reveal the priority of investigating the probable modulatory mechanism of these factors in COVID-19 era. Therefore, this paper addresses the hypotheses suggested above expecting that moderate intensity aerobic exercise training approach will add new vision for an improved control of COVID-19 in the general population.

\section{ACE1 AND ACE2 GENES IN COVID-19}

Significant interindividual variability in susceptibility to severe respiratory infection and disease along with vaccines against infections has been related to extrinsic (socioeconomic status, nutrition, and co-exposures/infections) and intrinsic (age, sex, pre-existing disease, and genetic background) factors (Verhein et al., 2018). Susceptibility of individuals, induced by gene-environment interactions, plays an important role in regulating immunity, survival, and treatment responses in patients from various countries (Gemmati et al., 2020).

ACE1 and ACE2 collaboration in the RAS results in adjustment of the vasoconstrictor/proliferative (ACE1/AngII/AT1R) and vasodilator/antiproliferative (ACE2/Ang1-7/MAS$\mathrm{R}$ axis) actions (Gemmati et al., 2020).

Ang-(1-7) has been shown to reverse the actions of Ang II and mediates vasodilation, antitrophic effects, and bradykinininduced vasodilation (Ocaranza and Jalil, 2012). Increased ACE1/ACE2 ratio and in fact a shift toward ACE/Ang II/AT1R leads to the progression of different complex diseases such as hypertension, atherosclerosis, heart or kidney failure, and severe acute respiratory distress (Gemmati et al., 2020). An interaction between higher ACE2 and Ang-(1-7) and releasing vasoactive factors, such as nitric oxide (NO), prostaglandins, and bradykinin has been suggested, which can reduce the vascular resistance and improve blood flow (Carvalho et al., 2007). Furthermore, a high ACE2/ACE1 ratio preserves vascular endothelial function and exogenous ACE2 activation improves antithrombotic properties as seen in known ACE inhibitor (ACEi) and AT1-receptor blockers (ARB) namely captopril and losartan (Olkowicz et al., 2015). RAS inhibitors increase ACE2 levels to conserve organs from Ang II overload, which keeps the heart across different stresses and may assist patients with COVID-19 with cardiovascular diseases (CVDs) (Ferrario et al., 2020). Rising ACE2/Ang 1-7/Mas-R axis and preventing ACE2 shedding (i.e., ACEis and ARBs) have been presented as potential disease-modifying therapies to minimize greater severity in males (Viveiros et al., 2021).

Prior to the SARS-CoV-2 global pandemic, there were two other lethal CoV outbreaks namely SARS-CoV in 2003 and Middle East respiratory syndrome CoV (MERS-CoV) in 2012. SARS-CoV-2 shares almost $79.5 \%$ genomic homology with SARS-CoV and about 50\% similarity with MERS-CoV (Lu et al., 2020). The cellular receptor of SARS-CoV-2 and SARS-CoV is ACE2 (Hoffmann et al., 2020; Zhang et al., 2020). Upon binding, viral entry speeds up by the activation of the viral spike (S) protein by a specific transmembrane serine protease 2 (TMPRSS2) that are easily imported in lung tissue (Hoffmann et al., 2020; Zhang et al., 2020).

A decreased AngII/Ang-(1-7) ratio in the renal artery led to lower vasoconstriction and arterial blood pressure (Silva et al., 2015). A high ACE2/ACE1 ratio could explain increased protection against endothelial dysfunctions and vascular disorders, and probably leads to decreased capillary permeability, coagulation, fibrosis, and apoptosis in the alveolar cells, decreasing lung damage sparked by the SARS-CoV-2 (Gemmati et al., 2020). The ACE2 expression in lung facilitates the SARS-CoV-2 entry into lung cells during the infection, so it has a positive correlation with greater risk for evolving the severe form of COVID-19 (Pinto et al., 2020). Viral load is a measure of the amount of virus in an infected person's given volume of body fluids and is proposed as a way to detect risk of disease severity in COVID-19. In a complete analysis of respiratory tract, plasma, and urine, a correlation between greater prevalence of detectable SARS-CoV2 plasma viral load and poor respiratory situation and higher inflammation markers (C-reactive protein and IL-6) has been detected (Fajnzylber et al., 2020).

It has been demonstrated that high amount of circulatory ACE2 blocks the SARS-CoV protein binding to its receptor (Vaduganathan et al., 2020). This is in agreement with some studies announcing that ACE2 protects from COVID-19 outbreak (Brojakowska et al., 2020; Chen et al., 2020). The higher primary level of ACE2 in Asian females than in men in line with higher case of fatality in men and lower severity in females suggest a conservative effect of ACE2 on COVID-19 (Chen et al., 2020).

Low prevalence of COVID-19 in premenopausal women in comparison with postmenopausal women or age-matched men, indicates a protective part for estrogen (Wang et al., 2021). The estrogen interacts with the RAS, by prohibiting or downregulating renin, ACE, and AT1-R (Viveiros et al., 2021). Besides, a further $\mathrm{X}$ chromosome in females than males is a favorable factor, as several genes associated with immune system are related to $\mathrm{X}$ chromosome (Viveiros et al., 2021).

Acute respiratory distress syndrome (ARDS) generated by lower respiratory tract infection leads to a large majority of COVID-19-related deaths (Menter et al., 2020). Patients with Type 2 diabetic (T2D) due to RAS overactivation are more susceptible to serious SARS-CoV-2 infections and ARD (Zhu et al., 2020). Also RAS is overexpressed in obesity (Jia et al., 2020), but it was demonstrated that RAS overactivation in T2D was independent of obesity (Moin et al., 2020). 
Obesity indicates an excessive fat accumulation that presents a risk to health especially weak immune system related to serious health conditions (Wang et al., 2020). Approximately, 73\% of COVID-19 confirmed cases were overweight or obese with body mass indexes (BMI) over $25 \mathrm{~kg} / \mathrm{m} 2$ [Intensive Care National Audit and Research Centre (ICNARC), 2020]. There was also a positive relationship between the severity of SARS-CoV-2 and a BMI > 30 (Chiappetta et al., 2020). In a recent study, more than one half (50.8\%) of severe COVID-19 cases were obese, classified into four BMI categories, which emphasizes a dose-response link between higher BMI and severe COVID-19 symptoms (Kompaniyets et al., 2021). A meta-analysis showed that obese patients have a higher risk of COVID-19 hospitalization and mortality (Cai et al., 2021).

Angiotensin converting enzyme 2 as a receptor for SARS$\mathrm{CoV}-2$ is allocated in different human tissues, including adipose tissue (AT). So, a great deal of concentration should be provided on the obese people during the COVID-19 outbreak (Jia et al., 2020).

Besides, the AT incorporates several pro-inflammatory cytokines, which can decline the immune response and, thus, could result the relationship between obesity and the severity of COVID-19 (Al-Benna, 2020; Li, 2020). Obesity increases leptin and decreases adiponectin levels. This inequality causes dysfunction in immune function (Luzi and Radaelli, 2020). Leptin as a cytokine can have pro-inflammatory behavior that affects both innate and adaptive immune responses via stimulating the generation of IL- 2 and TNF- $\alpha$ and inhibiting the activation of IL-4 and IL-5 (Ali and Sood, 2012). Contrarily, adiponectin is an adipokine that utilizes anti-inflammatory actions that suppresses TNF- $\alpha$, IL-6, and nuclear factor- $\kappa \mathrm{B}$ $(\mathrm{NF}-\kappa \mathrm{B})$ and induces $\mathrm{IL}-10$ and $\mathrm{IL}-1$ receptor antagonist (Ali and Sood, 2012).

Regular exercise leads to a negative energy balance and decreases body fat (Gleeson et al., 2011). Regular daily exercise causes training adaptation, which boosts anti-inflammatory activity notably, while along with weight loss (Simpson et al., 2020; Calabrese and Neiman, 2021). The existence of a deleterious microbiota profile in obesity was demonstrated (Quiroga et al., 2020), emphasizing the importance of exercise approach as a potent non-pharmacological strategy in early obesity (Quiroga et al., 2020).

\section{PHYSICAL EXERCISE AND COVID-19}

Social distancing has been the initial plan for opposing COVID19 in many countries (Gasmi et al., 2020). As a result, the world is facing a new challenge, which is the limited use of PE (Filgueira et al., 2021).

The COVID-19 manifestations vary from mild to severe, which depends on the individual's different metabolic status, provided the age, sex, medical conditions, and lifestyle (Gasmi et al., 2020). Within the several lifestyle factors, exercise deserves a particular consideration. The effect of PE on boosting immune health and preventing infectious diseases (Walsh and Oliver, 2016) and as a useful complementary tool for recovery and prevention against COVID-19 and decreasing its severity (Wang et al., 2020) was suggested. The data suggest that physical inactivity influences the number of infected persons in the older population (Filgueira et al., 2021).

The various health benefits provided by exercise and its safety in asymptomatic people is a good reason to exercise during the CoV outbreak (Zhu, 2020). Experimental studies supported the main idea that $\mathrm{PE}$ can cause a shift toward the protecting arm ACE2/Ang 1-7/Mas-R upregulation, whereas concurrently downregulate the ACE/Ang II/AT1-R (Nunes-Silva et al., 2017; Evangelista, 2020).

Exercise has a major effect on susceptibility to infection (Nieman and Wentz, 2019), especially in people susceptible to infectious complications such as autoimmune inflammatory rheumatic diseases (AIIRD), who have immune dysfunction and are at high risk for acute respiratory viral infections and severe COVID-19 (Calabrese and Neiman, 2021). Regular exercise activity has not only protective effects against SARSCoV-2 infection, but also reduces the severity of infectious events (Grande et al., 2020). Regarding influenza infection, exercise is related to a reduced risk of mortality (Wong et al., 2008). Further, reduced risk of infection and an enhanced immunological response to vaccination are some noticeable clinical outcomes of exercise (Kohut et al., 2004; Weinhold et al., 2016). So the possibility of physical activity to increase the antibody and $\mathrm{T}$ cell response to COVID-19 vaccines, specifically in situations experiencing weakened vaccine efficacy like obesity, old age, and inflammation of the joints in arthritis disease (Nieman and Wentz, 2019) and AIIRD (Calabrese and Neiman, 2021), has been proposed. Regular exercise lowers enrollment of leukocytes to AT and consequently lowers the proinflammatory state of AT and cause a shift to anti-inflammatory phenotype of many immune cells (macrophages, monocytes, T-cells) (Gleeson et al., 2011).

The interaction between exercise and components of the ACE2/Ang 1-7/Mas-R axis depends on the study design, exercise protocol, intensity, and duration (Nunes-Silva et al., 2017). However, still no data exist in the literature on the exercise mode or intensity to prevent COVID-19.

\section{IMPACT OF AEROBIC EXERCISE ON RAS}

Aerobic exercise has been suggested as a potential stressor in the cells of healthy athletes (Nieman, 1994), which cuts down the risk of developing systemic inflammatory processes and stimulates cellular immunity (Nieman and Wentz, 2019).

A shifted RAS balance toward the ACE2/Ang 1-7/Mas receptor axis after aerobic $\mathrm{PE}$ was the reason for defensive outcomes facing obesity, insulin resistance, inflammation, high total cholesterol, and triacylglycerol levels (Frantz et al., 2017). Aerobic exercise was proposed as a useful strategy to lower body fat percentage and boosts the skeletal muscle capacity to use oxygen (Booth and Winder, 2005). Continuous aerobic exercise decreases the risk of metabolic disorders (Booth and Winder, 2005; Pedersen and Saltin, 2006). In a study comparing resistance 
and aerobic exercises, it was shown that the aerobic exercise was more potent in reducing adipose tissue (Slentz et al., 2011). Further, Silva et al. (2017) demonstrated that aerobic PE lowered Ang II and increased Ang 1-7 levels in left ventricular and plasma, adjusted oxidative stress, enhanced antioxidant protection, lowered collagen deposition and inflammatory profile, and reduced blood pressure (Silva et al., 2017).

In a research on mice, the effect of aerobic PE and ACEi treatment on angiotensin pattern was investigated. The exercise training group was placed distinctly in a cage with running wheel (running spontaneously) for 8 weeks. ACEi therapy in combination with aerobic physical activity had a supplementary effect on raising the activity of the ACE2/Ang-(1-7) pathway and in lowering ACE/Ang II activity; suggesting the additive favorable effect of aerobic exercise in ACE-2/ACE ratio (Tyrankiewicz et al., 2021). In the pretraining period, the total ACE was lower in II than deletion/deletion genotype (DD) genotypes, but a similar decrease in total ACE activity in all three genotypes after the aerobic exercise training protocol was demonstrated (Alves et al., 2018).

If aerobic exercise lowers ACE1 activity, it is probable that it may lead to a high ACE2/ACE1 ratio, and as RAS is subject for local tissue homeostasis by anti-inflammatory, anticoagulant, and anti-proliferation, it may control the local trophic responses to viruses (Tikellis and Thomas, 2012), possibly COVID-19. Therefore, aerobic exercise may shift the balance in the RAS toward the potective arm [ACE2/Ang-(1-7) axis] and counterbalance ACE2 repression caused by SARS-COV-2.

\section{EXERCISE INTENSITY AND IMMUNE FUNCTION}

Various physical exercises regarding intensity and type have distinct outcomes on immune system (Nieman and Wentz, 2019). It was demonstrated that unaccustomed strenuous or prolonged exercise may diminish the immune defense function (Zhu, 2020). As such, avoiding long and stressful exercise sessions that one is not used to is recommended ( $\mathrm{Zhu}, 2020$ ). HIE possibly because of originating oxidants and suppression of immune system may be threatening and help to aggravate the COVID19 virus (Rahmati-Ahmadabad and Hosseini, 2020). In a human study, the acute response of two different exercise regimens of HIIE and moderate intensity continuous exercise (MICE) on plasma and urinary concentration of RAS components was investigated. The HIIE protocol comprised of a 5-min cycling at $60-70 \%$ of heart rate peak intensity proceeding by 10 sets of $30 \mathrm{~s}$ above $90 \%$ with $1 \mathrm{~min}$ of recovery and $3 \mathrm{~min}$ of cool down. The MICE was performed at a steady power equal to $60-70 \%$ of HRp and finished at the same total work of HIE. The results declared that: (1) acute aerobic exercise can balance plasma and urinary levels of ACE and ACE2 in healthy individuals; (2) the MICE protocol led to a higher increase in urinary levels of Ang-(1-7) compared with HIIE (Magalhães et al., 2020). It is probably because HIIE requires a higher demand on the anaerobic metabolism (identified by peak lactate) in comparison with MICE, in which aerobic metabolism is greater (identified by peak non-ester fatty acid) (Cabral-Santos et al., 2015).

An experimental study comparing the effect of different aerobic exercise intensities indicated that moderate intensity aerobic exercise, in comparison with high intensity one, causes a significant rise in fibronectin type III domain-containing protein 5 (FNDC5) and peroxisome proliferator-activated receptor gamma coactivator 1-alpha (PGC-1 $\alpha$ ) in the muscle tissue of obese Wistar rats (Attarzadeh Hosseini et al., 2021), leading to its antioxidant activity (Wang et al., 2016).

In another study on healthy young men, long-term HIIT [90\% maximum heart rate (HRmax), three times a week] but not moderate intensity continuous training (MICT) [70\% HRmax, five times a week)], deteriorated immune response by increasing TNF- $\alpha$ (Gerosa-Neto et al., 2016). Additionally, it was indicated that only MICT [not high intensity interval training (HIIT)] favor as a potential type of exercise in SARS-CoV-2 disease, as HIIT cause the repression of the immune system (Rahmati-Ahmadabad and Hosseini, 2020).

On the other hand, some studies have shown the positive effects of HIE on inflammatory factors (Campbell and Turner, 2018; Khaleghzadeh et al., 2020). Campbell and Turner (2018) claimed that acute vigorous exercise does not lead to harmful effect on immune system. In the study by Khaleghzadeh et al. (2020) male obese Wistar rats had done 8 weeks of HIIT, which caused a significant reduction in plasma IL-6, TNF- $\alpha$, and aspartate aminotransferase (AST). These conclusions are probably because the mentioned studies are either on highly fit subjects (Campbell and Turner, 2018) or on animals (Khaleghzadeh et al., 2020). It seems that having an athletic background might have led to adaptations, which could modify the training effect on immune function. Also, using animal models has limitations, such as species distinction and stress related with enforced exercise, which should be taken into account (Zhu, 2020). Due to the ethics and safety concerns, there are few studies on prolonged HIE in sedentary people (Zhu, 2020).

Endurance training-induced adaptations differ according to the modes of training employed (e.g., running, swimming, cycling), the training length (weeks, months), and the frequency, duration, and intensity of workout (Vellers et al., 2018). While moderate exercise may boost the immune system, exhausting exercise may weaken it. In a study on subjects participating in marathon, a rise in respiratory infection was indicated (Peters and Bateman, 1983), after which J-curve was suggested by Nieman (1994) in the 1990s to define the link between exercise intensity and upper respiratory tract infection (URTI) (Nieman, 1994), indicating that moderate intensity exercise boosts immune function whereas vigorous exercise weakens the immune activity (Walsh and Oliver, 2016). Also, after long vigorous exercise, a phenomenon called "open window" happens for 3 to $72 \mathrm{~h}$, diminishing immunity, resulting in higher incidence of airway infections 
(Nieman and Pedersen, 1999). Suppression of the immune response caused by vigorous exercise may be due to: (1) elevated number of neutrophils and the concurrent lowered number of lymphocytes in the blood; (2) defective phagocytosis and neutrophil function; (3) reduced release of reactive oxygen species (ROS); (4) reduced natural killer cell cytolytic activity (NKCA); and (5) declined immunoglobulin levels (Moreira et al., 2009). However, it is unclear whether exercise to exhaustion itself or other factors that increase the probability of exhaustion weaken the immune system. Nonetheless, athletes who train very hard typically suffer more frequent infections probably because their high training load increases psychological stress and interrupts their circadian rhythms (Simpson et al., 2020). It is suggested that in competitive sports, upper respiratory symptoms (URS) might be caused by noninfectious causes, which are related to extreme training or competition, for instance mental stress and anxiety, insufficient sleep, travel, dietary deficiency, and climate variations or migration of inflammatory cytokines, originating from the damaged skeletal muscle to the respiratory system (Walsh, 2018).

Besides from athletic populations, regular $\mathrm{PE}$ is a key protective factor to improve immune function, while inactivity weakens immunity (Nieman et al., 2011). In a study on 48,440 adult patients with COVID-19, self-reported physical activity level was used to categorize them in three groups (consistently inactive $=0-10 \mathrm{~min} /$ week, some activity $=11-149 \mathrm{~min} /$ week, and consistently active $\geq 150+\mathrm{min} /$ week). Inactive patients with COVID-19 had a higher risk of hospitalization, admission to the intensive care unit (ICU), and death than patients who were constantly active (Sallis et al., 2021). Even doing some physical activity reduced the likelihood of hospitalization, which is suggestive of beneficial effect of physical activity in pandemic period. Being consistently inactive led to higher risk for all outcomes and even exceeded the health risks of smoking and nearly all the chronic diseases (cancer, diabetes, hypertension, renal disease, cardiovascular disease, chronic obstructive pulmonary disease) investigated in this study, arguing physical inactivity as a threat for severe COVID-19 consequences (Sallis et al., 2021). A 12-month observational study on the activity level of 547 healthy adults (age 2070 years) found that moderate physical activity leads to approximately $20 \%$ reduction in URTI risk (Matthews et al., 2002). Physical fitness and moderate intensity training are related to improved types of immune markers and reduce premature mortality rate (Suzuki and Hayashida, 2021). Fit people who perform moderate intensity exercise on a regular basis showed decreased markers of chronic inflammation, the stronger and more durable immune response to vaccination, increased immunosurveillance, and a lower disease susceptibility (Simpson et al., 2020). In a cohort study on 2,690 adults, a significant dose-response relationship between having moderate [adjusted relative risk $(\mathrm{aRR})=0.43,95 \%$ confidence interval (CI): $0.25,0.75]$ and high $(\mathrm{aRR}=0.37,95 \% \mathrm{CI}: 0.16,0.85)$ cardiorespiratory fitness with lower COVID-19 mortality has been investigated (Christensen et al., 2021). It is suggested that PE can lower the danger, infectious period, and severity of viral infections (Laddu et al., 2021). In addition, the health benefit of an objective of $\geq 150$ min per week (an activity that requires moderate effort) was indicated by the American College of Sports Medicine (ACSM) [Bushman and American College of Sports Medicine (ACSM), 2017]. The proposed amount of physical activity in a universal strategy (from 2018 to 2030) by the World Health Organization (WHO) was modest to intense exercise, at least 5 days per week, each lasting 30-60 min [World Health Organization (WHO), 2018], indicating that $150 \mathrm{~min} /$ week physical activity duration is the initial amount for keeping health in the normal population.

\section{DEFINITION OF MODERATE INTENSITY EXERCISE}

Present interpretations and definitions of moderate to vigorous intensity exercise are ambiguous. Due to the multiple formats used for illustrating moderate and vigorous intensity exercise in the research literature, presenting intensity to health outcomes is demanding (MacIntosh et al., 2021).

Brisk walking, dancing, and gardening are practical examples for prescribing a moderate intensity activity (MacIntosh et al., 2021).

Heart rate is a prompt assessment of exercise intensity, which should be individualized to target an applicable relative intensity domain (MacIntosh et al., 2021). Heart rate ranges indicated relative to the individual maximal heart rate or percentage of heart rate reserve can be employed to prescribe moderate (40-59\% of aerobic capacity reserve or heart rate reserve) and vigorous (60-84\% of these reserves) exercise intensity (Warburton et al., 2007).

In case, the individualized testing is not available, rating of perceived exertion (RPE) with a scale of 6-20 can be used in which a mean value of $10.8 \pm 1.8$ would be at the boundary between moderate and vigorous intensity (Scherr et al., 2013). Another useful method is the talk-test. During exercise, rapid ventilation makes it rather challenging to achieve a conversation. Just below this intensity is considered moderate (Reed and Pipe, 2014).

Although exercising at a percentage of maximal volume of oxygen (consumption) $\left(\dot{\mathrm{V}}_{2 \max }\right)$ and heart rate reserve are surely more applicable than using an absolute speed or power output, or even metabolic equivalent (MET) (MacIntosh et al., 2021), applying a common percentage of those measures probably serves as a diverse degree of disturbance to homeostasis for various individuals (Iannetta et al., 2020). Such as, two individuals exercising at $70 \%$ of $\mathrm{V}_{2}$ max may have distinct levels of metabolic disturbance to homeostasis due to exercising in different exercise domains (Jamnick et al., 2020).

Exercise intensity can be given in absolute or relative terms (i.e., relative to body weight, maximal oxygen uptake, maximal heart rate, or heart rate reserve). The ability to maintain homeostasis during acute exercise and the chronic adaptation to training is influenced by genetics, fitness status, comorbidities, and other factors, so, prescription should be individualized based 
on the expected metabolic disturbance obtained by the exercise (MacIntosh et al., 2021).

\section{ANTI-INFLAMMATORY SIGNALING PATHWAYS OF MODERATE INTENSITY EXERCISE}

It is widely recognized that regular moderate intensity PE boosts the hosts immunocompetence and preserves against infectious diseases (Alack et al., 2019).

Regular moderate intensity aerobic exercise (25-30 min per session/three times a week) for 10 months caused a significant rise in level (titer) of antibodies in the blood after influenza vaccination (Kohut et al., 2004). The effect of moderate intensity exercise on reducing prevalence of acute respiratory infections as well as the common cold, influenza, pneumonia, and COVID-19 has been proposed (Calabrese and Neiman, 2021). Immune response to influenza vaccination has been improved in individuals performing long-term exercise training (Nieman and Wentz, 2019; Valenzuela et al., 2021).

Different molecular pathways about anti-inflammatory effects of $\mathrm{PE}$ as a non-pharmacological intervention have been investigated.

One of the crucial parts of the inflammatory mechanism is cytokine originated by the innate macrophages, dendritic cells, natural killer cells, and $\mathrm{T}$ and $\mathrm{B}$ lymphocytes (Ragab et al., 2020). Moderate aerobic exercise training increases $T$ cell count that is reduced in SARS-CoV-2-infected patients (Li, 2020). Cytokines are classified as pro-inflammatory (e.g., IL-1, IL-6, and TNF- $\alpha$ ) and anti-inflammatory (e.g., IL-10 and IL-1 receptor antagonist) (Ragab et al., 2020); the latter can be modified due to physical exercise. Active skeletal muscle develops different cytokines and peptides with anti-inflammatory properties (Alack et al., 2019). Muscle-derived IL-6 does not act as an inflammatory cytokine, but rather as an anti-inflammatory myokine that acts in a hormone-like pattern and eliminates endocrine effects in other organs. IL-6 prompts the generation of anti-inflammatory cytokines such as interleukin-1 receptor antagonist (IL-1ra) and IL-10 (Steensberg et al., 2003), soluble TNF- $\alpha$ receptors (Krüger et al., 2016), and inhibits the endotoxininduced TNF- $\alpha$ production (Steensberg et al., 2003). A systematic review supported the fact that aerobic exercise advances the immune markers including leukocytes, lymphocytes, lymphocyte subpopulations, ILs, NK cells, and immunoglobulins in healthy individuals (Gonçalves et al., 2020). A destructive inflammatory response with the increased levels of cytokines, a critical lifethreating condition known as "cytokine storm," was detected in patients with severe COVID-19 (Ragab et al., 2020). The overproduction of pro-inflammatory cytokines leads to multiple organ damage if remains uncontrolled (da Silveira et al., 2021). In the lung, alveolar macrophages and epithelial cells are the utmost subject for over-generating of cytokines, which cause alveolar damage due to wall thickening (da Silveira et al., 2021). When SARS-COV-2 causes URTI, it leads to the generation of proinflammatory cytokines, including IL-1 $\beta$ and IL- 6 , causing mild or severe URTI (Shi et al., 2020). Not only young, but also old active people ( $>65$ years) gain from exercising by an increasing $\mathrm{T}$ cell proliferation, NK cell cytotoxicity, and neutrophil phagocytic activity (Walsh et al., 2011).

Regular aerobic exercise reduces the basal concentration of inflammatory cytokines and pro-inflammatory $\mathrm{T}$ effector memory CD45+ re-expressing T cells (T-EMRA cells), and inhibits the stimulation of thrombotic pathways (Philippe et al., 2019). Over moderate and intensive aerobic exercise bouts of shorter than $60 \mathrm{~min}$, a significant rise in anti-inflammatory cytokines, neutrophils, NK cells, cytotoxic T cells, and immature $\mathrm{B}$ cells occur that have major effect in immune response (Nieman and Wentz, 2019). In a study conducted on two independent groups with cycling as their exercise modality $\left(80 \% \mathrm{~V}_{2} \max \right.$ for $20 \mathrm{~min})$ vs. ( $+5 \%$ of the individual blood lactate threshold for $30 \mathrm{~min}$ ), the number of peripheral blood B lymphocytes doubled during these acute exercises with a mean increase of 88 and 60\%, respectively (Turner et al., 2016). Regular endurance exercise, such as running or walking, has been generally recognized as a way to rise CD $4+/ \mathrm{CD} 8+$ ratio in older adults (Walsh et al., 2011).

A study on rats demonstrated that aerobic exercise led to $50 \%$ increase in AMP-activated protein kinase (AMPK) activity (Budinger et al., 2008), which attenuates pro-inflammatory cytokines in airway epithelial cells by inhibiting the NF- $\mathrm{KB}$ system (Cholewa and Paolone, 2012). Furthermore, AMPK activation leads to ACE2 phosphorylation and increases Ang 17 in pulmonary endothelium cells (Zhang et al., 2018). Regular moderate exercise caused the conversion of Ang II to Ang 17 and reduced pulmonary fibrosis via ACE2/Ang-(1-7)/Mas receptor pathway (Prata et al., 2017). In this regard, exercise may prevent the destructive outcomes of binding SARS-CoV-2 to ACE2 receptor, lowering the pro-inflammatory response in the pulmonary system (Zbinden-Foncea et al., 2020).

Exercise leads to a stimuli of cortisol, principal stress hormone with a potent anti-inflammatory characteristics (Gleeson et al., 2017). Lower cortisol and higher interferon gamma (IFN$\gamma$ ) levels after exercise (30 min cycling at $115 \%$ of their lactate threshold power) led to shifts in NK-cell subsets (Gupta et al., 2018).

Also, there is a positive relationship between the integrity of gut microbiota and local, innate, and systemic immunity (Wiertsema et al., 2021). Microbiota profile was positively modified by exercise intervention (Quiroga et al., 2020). Evidence demonstrates that exercise-induced increase in gut microbiota leads to an improved immune function, which is higher in trained athletes compared with control group (Barton et al., 2018; Mailing et al., 2019).

Exercise reduces the NLR family pyrin domain containing 3 (NLRP3) inflammasome, a key component of the innate immune system that initiates caspase-1 activation, which is an inflammatory form of cell death and the release of proinflammatory cytokines IL-1 $\beta$ and IL-18 (Quiroga et al., 2020; Ding and $\mathrm{Xu}, 2021)$. It was recommended that aerobic exercise is the most effective training modality, and low-to-moderate intensity and mixed intensity are better compared with high intensity to decrease NLRP3 inflammasome activation-related inflammatory cytokine IL-1 $\beta$ and IL-18 (Ding and Xu, 2021). 
One more mechanism through which exercise promotes an anti-inflammatory response is a downregulation of pro-inflammatory toll-like receptors (TLRs) (Abbasi et al., 2014). Aerobic exercise reduces the expression/activation of TLR4 on the surface of monocytes (Lancaster et al., 2005). Since these monocytes are the predecessors of tissue macrophages, the exercise-induced decline in monocyte TLR4 expression is probably a key mechanism to the antiinflammatory responses of exercise (Collao et al., 2020). Exercise led to the downregulation of TLR4 (Quiroga et al., 2020). The interaction between the microbiota and the TLRs and NLRP3 inflammasome activation, resulting in low-grade inflammation, is well-established (Quiroga et al., 2020).

Physical exercise activates peroxisome proliferatoractivated receptor coactivator 1 alpha (PGC-1 $\alpha$ ) pathway, a signaling factor that is associated with decreasing pathological myocardial remodeling, lowering blood pressure and decreased deposition of collagen (Whitehead et al., 2018), as well as reducing systemic inflammatory profile by preventing the infiltration of macrophages, TNF- $\alpha$, and inducible nitric oxide synthase (iNOS), involving inhibition of cytokines and pro-inflammatory factors in the blood (Botta et al., 2013). PGC-1 $\alpha$ results in the elevated expression of FNDC5, which release Irisin (Reza et al., 2017).

Also, by accumulation of neutrophils, the creation of ROS and pro-inflammatory molecules raises (Yan and Spaulding, 2020), which are associated with acute lung injury, the most common cause of morbidity and mortality in COVID-19 (Nobari et al., 2021b). Mitochondria is a place for ROS production and exercise is a potent mediator of ROS (Nobari et al., 2021a). Irisin is a skeletal muscle myokine (Nobari et al., 2021a), which could play a role in anti-oxidative pathways involving the transcription factor nuclear factor erythroid 2related factor 2 (Nrf2) (Wang et al., 2016), and even on the expression of many distinct genes related to SARS-CoV2 infection (de Oliveira et al., 2020). Irisin has a positive correlation with improved lung function (Nobari et al., 2021b). Furthermore, Nrf2 results in the transformation of cells subject to oxidative stresses (Ruhee and Suzuki, 2020). In normal circumstances, Nrf2 is placed in the cytoplasm bound to its Keap1, which is its inhibitor, and leads to consequent degradation of Nrf2. When ROS is available, the connection between Kelch like ECH associated protein 1 (Keap1) and Nrf2 detaches and Nrf2 moves to the nucleus, where it arouses the antioxidant feedback (Ruhee and Suzuki, 2020). Exercise causes Nrf2 migration to the nucleus, and this arouses antioxidant and anti-inflammatory activity (Wang et al., 2016; Figure 2).

Considering that the universal concern about chronic diseases is constantly increasing, the advancement of approaches to a life-long rise in regular physical activity at the social level is required (Alack et al., 2019). Generally, the direct and indirect anti-inflammatory effects of moderate intensity aerobic exercise cause a great percentage of its preventive and therapeutic capacity. The fact that exercise intervention is able to induce a fundamental change in downstreaming immune responses could be used to develop concepts that could influence the development and treatment success of infectious diseases.

\section{RETURNING TO EXERCISE TRAINING AFTER COVID-19 RECOVERY}

Many recovered patients with COVID-19, notably those manifesting severe symptoms during the infection phase, are not able to improve functional life, a sign of returning to the normal life after being discharged (Giallauria et al., 2018). Subsequently, slow and gradual return to the earlier level and at the same time being cautious about any clinical or cardiovascular symptoms have been indicated (Salman et al., 2021). Once the person has recovered from COVID19, safety-focused physical activity approaches should be considered to reduce the likelihood of risks. After recovering from COVID-19, physical and psychological situation of the individual play a key role for returning to activity (Salman et al., 2021).

A week from COVID-19 symptom onset, generally a decline in severe infection occurs (Salman et al., 2021). Accordingly, a return to $\mathrm{PE}$ is only allowed following at least 7 days symptomfree period (Barker-Davies et al., 2020).

In a study on performance athletes who had mild-tomoderate illness, it was recommended that anaerobic sports like golf can be performed earlier but before restarting aerobic exercise, daily routine activities should be obtained comfortably and a $500 \mathrm{~m}$ walk on the flat surface should be easily achievable without feeling extra fatigue or difficulty in breathing (Elliott et al., 2020). Nonetheless, as some people may not be able to walk 500 ?m without shortness of breath in the normal situation, dealing with the individual's pre-COVID-19 baseline ability has been suggested (Salman et al., 2021).

The people who performed recreational exercise activities for general physical fitness preillness, after recovering from COVID-19 with mild-to-moderate manifestations, without hospitalization and concerning heart-related symptoms should be able to proceed moderate intensity recreational exercise according to physical activity guidelines for Americans (Calabrese and Neiman, 2021; Salman et al., 2021), which recommends changing sedentary behaviors by moving more and sitting less, getting at least $150 \mathrm{~min}$ of moderate aerobic activity or $75 \mathrm{~min}$ of vigorous aerobic activity per week and performing exercises that develop muscular strength on two or more days a week (Piercy et al., 2018).

Generally, recovery from respiratory viral infections takes 2-3 weeks, which is related to the time it takes your immune system to develop cytotoxic $\mathrm{T}$ cells crucial to clear the virus from infected cells. After this period, when symptoms are over, it is safe to start exercising on a routine basis, but it is suggested to start slowly 


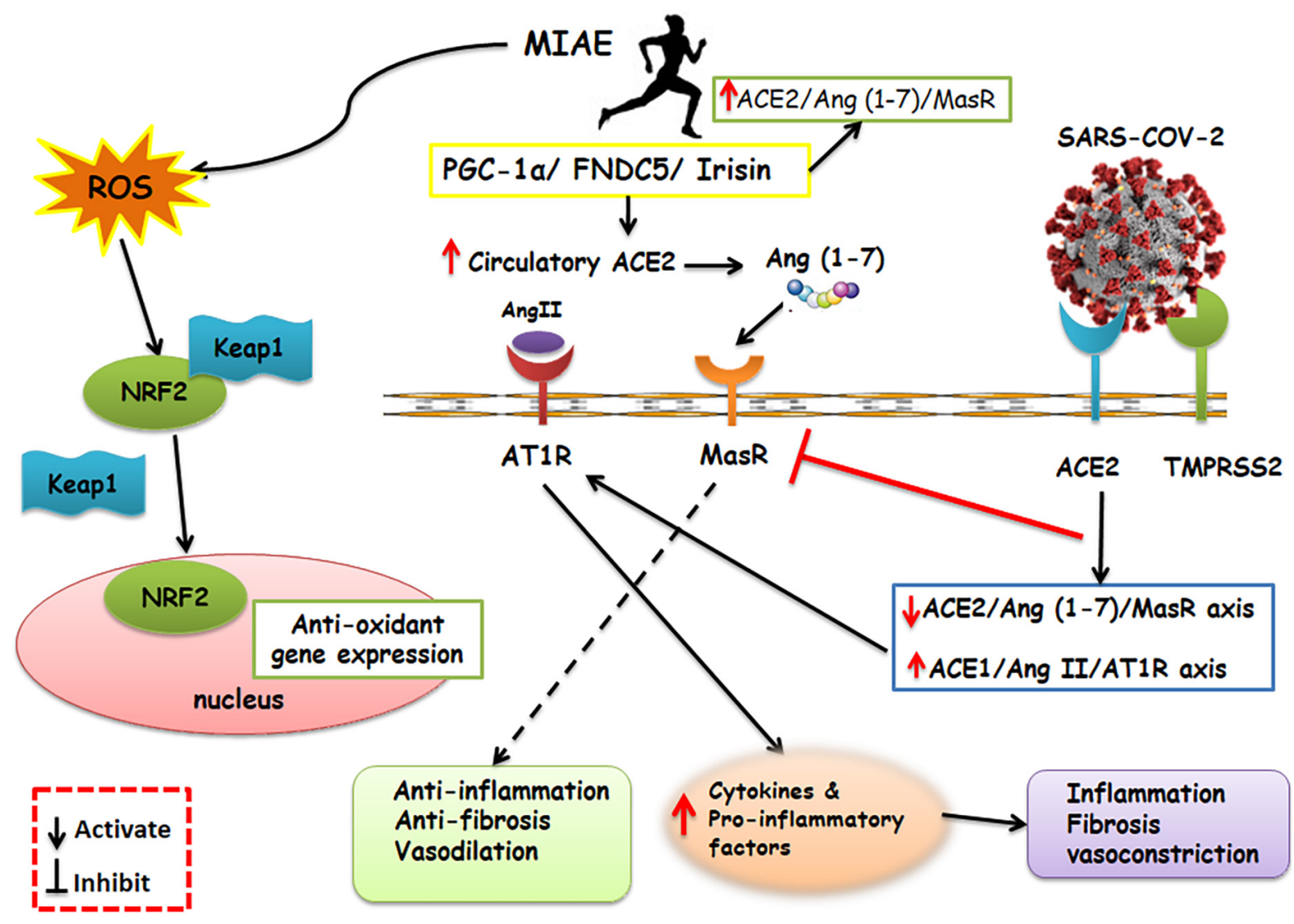

FIGURE 2 | Schematic representation of the main molecular pathways activated by SARS-CoV-2 and aerobic physical exercise and their respective consequences. On the right of the panel, the SARS-CoV-2 is shown, which relies upon ACE2 and TMPRSS2 to enter the host cells. SARS-CoV-2 upregulates the expression of ACE1/Ang-II/AT1R and inhibits the MasR which results in exacerbating inflammatory response. Contrarily, a shifted RAS balance toward the ACE2/Ang 1-7/Mas receptor axis after aerobic physical exercise was a reason for defensive outcomes. Furthermore, exercise activates PGC-1 $\alpha$-FNDC5//risin pathway. Irisin play an important role in anti-inflammatory pathways including Nrf2. Nrf2 results in transformation of cells subject to oxidative stress. In normal circumstances, Nrf2 is placed in the cytoplasm bound to its Keap1, which is its inhibitor. When ROS caused by exercise is available, the Keap1 and Nrf2 connection detaches and Nrf2 moves to the nucleus, where it arouses the antioxidant and anti-inflammatory activity. MIAE, Moderate intensity aerobic exercise; ACE2, Angiotensin converting enzyme2; Ang II, Angiotensin II; Ang 1-7, Angiotensin 1-7; AT1R, Angiotensin II receptor type 1; MAS R, Mas receptor; ROS, Reactive Oxygen Species; FNDC5, fibronectin type III domain-containing protein 5; PGC-1 $\alpha$, Peroxisome proliferator-activated receptor gamma coactivator 1-alpha; TMPRSS2, Transmembrane serine protease 2; Nrf2, nuclear factor erythroid 2-related factor 2; KEAP1, Kelch-like ECH-associated protein 1.

(Zhu, 2020). However, definite recommendations are not available at present.

\section{EXERCISE TRAINING IN THOSE WITH ACTIVE COVID-19}

During the acute phase of infection, exercise may cause increased viral replication, an intense pro-inflammatory response ending in heightened cellular necrosis (Kiel et al., 1989). After COVID-19 disease, due to the spread of infection, the patients will not be able to exercise (Zhu et al., 2020; Nobari et al., 2021a). Hence, it was recommended to cease exercise in case of active COVID-19 infection and the presence of any of the following symptoms: severe sore throat, body aches, shortness of breath, general fatigue, chest cough, or fever (Zhu, 2020). Clinical features of COVID-19 have been classified into: mild [no dyspnea, no low blood oxygen saturation (SatO2)], moderate (dyspnea, SatO2 94 to $98 \%$, radiological signs of pneumonia), severe (dyspnea, SatO2 $\leq 93 \%$, respiratory rate $(\mathrm{RR})>30 / \mathrm{min}$, radiological progression of lesions, with $\mathrm{O} 2$ supplementation required, eventually with non-invasive ventilation), and critical (patients need mechanical ventilation) (Carda et al., 2020). According to several reports, the lungs are exposed to the virus in severe patients with COVID-19, so these individuals are completely unable to exercise; however, in patients with mild disease, short-term moderate exercises can be a good solution (Zhu, 2020).

A myocardial injury due to COVID-19 has been proposed, which is a combination of early acute phase of viral induced myocarditis and a sub-acute pro-inflammatory response leading to cardiac damage (Siripanthong et al., 2020). Over the chronic phase, clinical manifestations of SARS-CoV-2 myocarditis range 
from relatively mild symptoms, like fatigue and dyspnea (Inciardi et al., 2020), chest pain, or chest tightness on exertion (Zeng et al., 2020) to heart failure (Inciardi et al., 2020). In case of heart manifestations (palpitations, syncope, chest pain, dyspnea, unexplained increase in heart rate) after COVID-19 infection, avoid moderate to high intensity exercise (McKinney et al., 2021). About $7-20 \%$ of sudden cardiac deaths (SCD) in young athletes are due to myocarditis (Maron et al., 2016). So, a more cautious approach should be applied when returning to exercise after myocarditis. During COVID-19 with myocarditis and even 36 months after recovery, strenuous activity and exercise should be restricted (McKinney et al., 2021).

Besides, COVID-19, which is initially a respiratory disease, has the potency to convert into a motor impairment after acute stages, associated with the length of time the patient spends in intensive care (Piquet et al., 2021). Many COVID-19 patients experience serious motor loss (Hekmatikar et al., 2021), severe fatigue, and deficiency in the legs and arms muscles (Islam et al., 2020), so they may suffer from muscle atrophy and physical impairment, which leads to limited movement and loss of muscle function. In this context, exercise could potentially play a key role during recovery from COVID-19.

Inpatient rehabilitation for patients with COVID-19 was associated with significant functional and respiratory enhancement, especially in severe cases (Piquet et al., 2021). Also, a recent study proposed that rehabilitation and breathing exercises in patients are effective in preventing muscle atrophy or at least its rapid progression (Nobari et al., 2021a). A systematic review with meta-analyses showed that aerobic training combined with breathing exercises led to significant advancement in exercise capacity, dyspnea, and quality of life in patients with idiopathic pulmonary fibrosis (Hanada et al., 2020).

Nevertheless, because of respiratory tract infection, achieving aerobic exercises for patients with COVID-19 would be exceedingly tough. Accordingly, skeletal muscle exercise with minimum lung involvement such as isometric training (muscle contraction with muscle-tendon unit at a constant length), which includes $5-10$ repetitions of $5 \mathrm{~s}$ per contraction, 5 days per week should be preferred (Khoramipour et al., 2021; Nobari et al., 2021a).

Besides, as lung is the eventual organ affected by SARS-COV2 , it is vital to target exercise approaches on cardiorespiratory muscle training to enhance respiratory function (Rothan and Byrareddy, 2020). Respiratory muscles like other muscles respond to stimulation (Suzuki, 2019). Rising respiratory load is investigated as the primary stimulation for these muscles and can cause developed strength and endurance (Vargas-Mendoza et al., 2019). Respiratory muscle training (RMT) is an applicable method to enhance respiratory and exercise performance, which incorporates (1) decreased respiratory muscle fatigue, (2) delayed respiratory muscle metaboreflex activation, and (3) improved $\mathrm{SaO} 2$ preservation and blood supply to active muscles (ÁlvarezHerms et al., 2019), all of which are exactly desirable outcomes for patients with COVID-19. A 2-week RMT promoted pulmonary function, dyspnea, and functional performance in recovered ICU patients with COVID-19 after ensuring removing mechanical ventilation (Abodonya et al., 2021). So it was recommended to include RMT program in the COVID-19 management approaches, especially in ICU patients (Abodonya et al., 2021).

\section{CONCLUSION}

Aerobic moderate intensity PE shows the potential as a novel non-pharmacological intervention against COVID-19 pandemic. In the context of previously reported studies, we hypothesized that the physiological responses associated with aerobic exercise elicit effects that could stimulate the ACE2-Ang-(1-7)-Mas receptor axis and anti-inflammatory responses, which act in favor of the immune system and even promote potent effects against infectious diseases like COVID-19. Whether aerobic exercise increases ACE2 expression and whether it adjusts susceptibility to SARS-CoV-2 and the severity of COVID19 disease should be considered in large groups. Along with scientific evidence provided here, healthy individuals will take advantage from aerobic moderate intensity exercise and will improve immune function, which will be a relevant asset in struggle against COVID-19.

Further experimental and clinical researches of the definite role of aerobic PE and its rule in RAS system and anti-inflammatory process are necessary to address its probable advantage and beneficial effect on prevention against COVID-19. However, the available evidence strengthens the recommendation for moderate intensity $\mathrm{PE}$ as an effective strategy during the pandemic period for various reasons, namely, lowering the metabolic and cardiovascular risk factors. In this way, the aerobic moderate intensity exercise prescription would diminish future confusion about this disease, and should be highly advocated in healthy individuals.

\section{DATA AVAILABILITY STATEMENT}

The original contributions presented in the study are included in the article/supplementary material, further inquiries can be directed to the corresponding author/s.

\section{AUTHOR CONTRIBUTIONS}

HA and AF conceptualized the perspective idea. AF prepared first draft of the manuscript. HA and KS revised the text of the manuscript. All authors read and approved the final version of the manuscript.

\section{FUNDING}

This study was supported by the Scientific Research (A) (20H00574) from the Ministry of Education, Culture, Sports, Science, and Technology of Japan. 


\section{REFERENCES}

Abbasi, A., Hauth, M., and Walter, M. (2014). Exhaustive exercise modifies different gene expression profiles and pathways in LPS-stimulated and unstimulated whole blood cultures. Brain Behav. Immun. 39, 130-141.

Abodonya, A. M., Abdelbasset, W. K., Awad, E. A., Elalfy, I. E., Salem, H. A., and Elsayed, S. H. (2021). Inspiratory muscle training for recovered COVID19 patients after weaning from mechanical ventilation: a pilot control clinical study. Medicine 100:e25339. doi: 10.1097/MD.0000000000025339

Alack, K., Pilat, C., and Krüger, K. (2019). Current knowledge and new challenges in exercise immunology. Dtsch. Z. Sportmed. 70, 250-260.

Al-Benna, S. (2020). Association of high level gene expression of ACE2 in adipose tissue with mortality of COVID-19 infection in obese patients. Obes. Med. 19:100283. doi: 10.1016/j.obmed.2020.100283

Ali, A. N., and Sood, A. (2012). Leptin, adiponectin and pulmonary diseases. Biochimie 94, 2180-2189.

Álvarez-Herms, J., Julià-Sánchez, S., Corbi, F., Odriozola-Martínez, A., and Burtscher, M. (2019). Putative role of respiratory muscle training to improve endurance performance in hypoxia: a review. Front. Physiol. 9:1970. doi: 10. 3389/fphys.2018.01970

Alves, C. R., Fernandes, T., Lemos, J. R. Jr., Magalhães, F. C., Trombetta, I. C., Alves, G. B., et al. (2018). Aerobic exercise training differentially affects ACE Cand N-domain activities in humans: interactions with ACE I/D polymorphism and association with vascular reactivity. J. Renin Angiotensin Aldosterone Syst. 19:1470320318761725. doi: 10.1177/1470320318761725

Attarzadeh Hosseini, S. R., Fathi, M., Mosaferi Ziaaldini, M., and Hejazi, K. (2021). The effect of eight weeks of aerobic exercise with moderate and high intensities on serum irisin and PGC-1 $\alpha$ protein levels in obese male Wistar rats. J. Shahrekord. Univ. Med. Sci. 23, 14-19.

Banu, N., Panikar, S. S., Leal, L. R., and Leal, A. R. (2020). Protective role of ACE2 and its downregulation in SARS-CoV-2 infection leading to macrophage activation syndrome: therapeutic implications. Life Sci. 256:117905. doi: 10. 1016/j.lfs.2020.117905

Barker-Davies, R. M., O’Sullivan, O., Senaratne, K. P. P., Baker, P., Cranley, M., Dharm-Datta, S., et al. (2020). The Stanford Hall consensus statement for post-COVID-19 rehabilitation. Br. J. Sports Med. 54, 949-959.

Barton, W., Penney, N. C., Cronin, O., Garcia-Perez, I., Molloy, M. G., Holmes, E., et al. (2018). The microbiome of professional athletes differs from that of more sedentary subjects in composition and particularly at the functional metabolic level. Gut 67, 625-633.

Booth, F. W., and Winder, W. W. (2005). Highlighted topic: role of exercise in reducing the risk of diabetes and obesity. J. Appl. Physiol. 99, 3-4.

Botta, A., Laher, I., Beam, J., DeCoffe, D., Brown, K., Halder, S., et al. (2013). Short term exercise induces PGC- $1 \alpha$, ameliorates inflammation and increases mitochondrial membrane proteins but fails to increase respiratory enzymes in aging diabetic hearts. PLoS One 8:e70248. doi: 10.1371/journal.pone.0070248

Brojakowska, A., Narula, J., Shimony, R., and Bander, J. (2020). Clinical implications of SARS-CoV-2 interaction with renin angiotensin system: JACC review topic of the week. J. Am. Coll. Cardiol. 75, 3085-3095.

Budinger, G. R., Urich, D., DeBiase, P. J., Chiarella, S. E., Burgess, Z. O., Baker, C. M., et al. (2008). Stretch-induced activation of AMP kinase in the lung requires dystroglycan. Am. J. Respir. Cell Mol. Biol. 39, 666-672.

Burrell, L. M., Johnston, C. I., Tikellis, C., and Cooper, M. E. (2004). ACE2, a new regulator of the renin-angiotensin system. Trends Endocrinol. Metab. 15, 166-169.

Bushman, B., and American College of Sports Medicine (ACSM) (2017). ACSM's Complete Guide to Fitness \& Health, 2nd Edn, Champaign, IL: Human Kinetics.

Cabral-Santos, C., Gerosa-Neto, J., Inoue, D. S., Panissa, V. L., Gobbo, L. A., and Zagatto, A. M. (2015). Similar anti-inflammatory acute responses from moderate-intensity continuous and high-intensity intermittent exercise. J. Sport. Sci. Med. 14, 849-856.

Cai, Z., Yang, Y., and Zhang, J. (2021). Obesity is associated with severe disease and mortality in patients with coronavirus disease 2019 (COVID-19): a metaanalysis. BMC Public Health 21:1505. doi: 10.1186/s12889-021-11546-6

Calabrese, L., and Neiman, D. C. (2021). Exercise, infection and rheumatic diseases: what do we know? RMD Open. 7:e001644. doi: 10.1136/rmdopen-2021-001644

Campbell, J. P., and Turner, J. E. (2018). Debunking the myth of exercise-induced immune suppression: redefining the impact of exercise on immunological health across the lifespan. Front. Immunol. 9:648. doi: 10.3389/fimmu.2018. 00648

Carda, S., Invernizzi, M., Bavikatte, G., Bensmail, D., Bianchi, F., Deltombe, T., et al. (2020). The role of physical and rehabilitation medicine in the COVID19 pandemic: the clinician's view. Ann. Phys. Rehabil. Med. 63, 554-556. doi: 10.1016/j.rehab.2020.04.001

Carvalho, M. B., Duarte, F. V., Faria-Silva, R., Fauler, B., da Mata Machado, L. T., de Paula, R. D., et al. (2007). Evidence for Mas-mediated bradykinin potentiation by the angiotensin-(1-7) nonpeptide mimic AVE 0991 in normotensive rats. Hypertension 50, 762-767. doi: 10.1161/HYPERTENSIONAHA.107.094987

Chen, J., Jiang, Q., Xia, X., Liu, K., Yu, Z., Tao, W., et al. (2020). Individual variation of the SARS-CoV-2 receptor ACE2 gene expression and regulation. Aging Cell 19:e13168.

Chiappetta, S., Sharma, A. M., Bottino, V., and Stier, C. (2020). COVID-19 and the role of chronic inflammation in patients with obesity. Int. J. Obes. 44, 1790-1792.

Cholewa, J. M., and Paolone, V. J. (2012). Influence of exercise on airway epithelia in cystic fibrosis: a review. Med. Sci. Sports Exerc. 44, 1219-1226.

Christensen, R. A. G., Arneja, J., St. Cyr, K., Sturrock, S. L., and Brooks, J. D. (2021). The association of estimated cardiorespiratory fitness with COVID-19 incidence and mortality: a cohort study. PLoS One 5:e0250508. doi: 10.1371/ journal.pone.0250508

Collao, N., Rada, I., Francaux, M., Deldicque, L., and Zbinden-Foncea, H. (2020). Anti-inflammatory effect of exercise mediated by toll-like receptor regulation in innate immune cells - a review. Int. Rev. Immunol. 39, 39-25.

da Silveira, M. P., da Silva Fagundes, K. K., Bizuti, M. R., Starck, É, Rossi, R. C., de Resende, E., et al. (2021). Physical exercise as a tool to help the immune system against COVID-19: an integrative review of the current literature. Clin. Exper. Med. 21, 15-28.

de Oliveira, M., De Sibio, M. T., Mathias, L. S., Rodrigues, B. M., Sakalem, M. E., and Nogueira, C. R. (2020). Irisin modulates genes associated with severe coronavirus disease (COVID-19) outcome in human subcutaneous adipocytes cell culture. Mol. Cell Endocrinol. 15:110917. doi: 10.1016/j.mce.2020. 110917

Ding, Y., and Xu, X. (2021). Effects of regular exercise on inflammasome activationrelated inflammatory cytokine levels in older adults: a systematic review and meta-analysis. J. Sports Sci. 12, 1-15. doi: 10.1080/02640414.2021.1932279

Elliott, N., Martin, R., Heron, N., Elliott, J., Grimstead, D., and Biswas, A. (2020). Infographic. Graduated return to play guidance following COVID-19 infection. Br. J. Sports Med. 54, 1174-1175.

Evangelista, F. S. (2020). Physical exercise and the renin angiotensin system: prospects in the COVID-19. Front. Physiol. 11:561403. doi: 10.3389/fphys.2020. 561403

Fajnzylber, J., Regan, J., Coxen, K., Corry, H., Wong, C., Rosenthal, A., et al. (2020). SARS-CoV-2 viral load is associated with increased disease severity and mortality. Nat. Commun. 11:5493. doi: 10.1038/s41467-020-19057-5

Ferrario, C. M., Ahmad, S., and Groban, L. (2020). Mechanisms by which angiotensin-receptor blockers increase ACE2 levels. Nat. Rev. Cardiol. 17:378. doi: 10.1038/s41569-020-0387-7

Filgueira, T. O., Castoldi, A., Santos, L. E. R., de Amorim, G. J., de Sousa Fernandes, M. S., Anastácio, W. L. D. N., et al. (2021). The relevance of a physical active lifestyle and physical fitness on immune defense: mitigating disease burden, with focus on COVID-19 consequences. Front. Immunol. 12:587146. doi: 10. 3389/fimmu.2021.587146

Frantz, E. D. C., Medeiros, R. F., Giori, I. G., Lima, J. B. S., Bento-Bernardes, T., Gaique, T. G., et al. (2017). Exercise training modulates the hepatic reninangiotensin system in fructose-fed rats. Exp. Physiol. 102, 1208-1220. doi: 10. 1113/EP085924

Gasmi, A., Noor, S., Tippairote, T., Dadar, M., Menzel, A., and Bjørklund, G. (2020). Individual risk management strategy and potential therapeutic options for the COVID-19 pandemic. Clin. Immunol. 215:108409. doi: 10.1016/j.clim. 2020.108409

Gemmati, D., Bramanti, B., Serino, M. L., Secchiero, P., Zauli, G., and Tisato, V. (2020). COVID-19 and individual genetic susceptibility/receptivity: role of ACE1/ACE2 genes, immunity, inflammation and coagulation. Might the double $\mathrm{X}$-chromosome in females be protective against SARS-CoV-2 compared to the single X-chromosome in males? Int. J. Mol. Sci. 21:3474. doi: 10.3390/ ijms21103474 
Gerosa-Neto, J., Antunes, B. M. M., and Campos, E. Z. (2016). Impact of longterm high-intensity interval and moderate-intensity continuous training on subclinical inflammation in overweight/obese adults. J. Exerc. Rehabil. 12, 575-580. doi: 10.12965/jer.1632770.385

Giallauria, F., Piccioli, L., Vitale, G., and Sarullo, F. M. (2018). Exercise training in patients with chronic heart failure: a new challenge for cardiac rehabilitation community. Monaldi. Arch. Chest. Dis. Arch. Monaldi. Mal. Torace 88:987.

Gleeson, M., Bishop, N. C., Stensel, D. J., Lindley, M. R., Mastana, S. S., and Nimmo, M. A. (2011). The anti-inflammatory effects of exercise: mechanisms and implications for the prevention and treatment of disease. Nat. Rev. Immunol. 11, 607-615. doi: 10.1038/nri3041

Gleeson, M., Pyne, D. B., Elkington, L. J., Hall, S. T., Attia, J. R., Oldmeadow, C., et al. (2017). Developing a multi-component immune model for evaluating the risk of respiratory illness in athletes. Exerc. Immunol. Rev. 23, 52-64.

Gonçalves, C. A. M., Dantas, P. M. S., Dos Santos, I. K., Dantas, M., da Silva, D. C. P., Cabral, B. G. A. T., et al. (2020). Effect of acute and chronic aerobic exercise on immunological markers: a systematic review. Front. Physiol. 10:1602. doi: $10.3389 /$ fphys.2019.01602

Grande, A. J., Keogh, J., Silva, V., and Scott, A. M. (2020). Exercise versus no exercise for the occurrence, severity, and duration of acute respiratory infections. Cochrane Database Syst. Rev. 4:CD010596.

Gupta, P., Bigley, A. B., Markofski, M., Laughlin, M., and LaVoy, E. C. (2018). Autologous serum collected 1 ?h post-exercise enhances natural killer cell cytotoxicity. Brain Behav. Immun. 71, 81-92. doi: 10.1016/j.bbi.2018. 04.007

Hanada, M., Kasawara, K. T., Mathur, S., Rozenberg, D., Kozu, R., Hassan, S. A., et al. (2020). Aerobic and breathing exercises improve dyspnea, exercise capacity and quality of life in idiopathic pulmonary fibrosis patients: systematic review and meta-analysis. J. Thoracic Dis. 12, 1041-1055. doi: 10.21037/jtd. 2019.12.27

Heffernan, K. S., and Jae, S. Y. (2020). Exercise as medicine for COVID-19: an ACE in the hole? Med. Hypotheses 142:109835. doi: 10.1016/j.mehy.2020.109835

Hekmatikar, A. H. A., Shamsi, M. M., Ashkazari, Z. S. Z., and Suzuki, K. (2021). Exercise in an overweight patient with COVID-19: a case study. Int. J. Environ. Res. Public Health 18:5882.

Hoffmann, M., Kleine-Weber, H., Schroeder, S., Krüger, N., Herrler, T., Erichsen, S., et al. (2020). SARS-CoV-2 cell entry depends on ACE2 and TMPRSS2 and is blocked by a clinically proven protease inhibitor. Cell 181, 271-280.e8. doi: 10.1016/j.cell.2020.02.052

Iannetta, D., Inglis, E. C., Pogliaghi, S., Murias, J. M., and Keir, D. A. (2020). A "step-ramp-step" protocol to identify the maximal metabolic steady state. Med. Sci. Sports Exerc. 52, 2011-2019. doi: 10.1249/MSS.0000000000002343

Inciardi, R. M., Lupi, L., and Zaccone, G. (2020). Cardiac involvement in a patient with coronavirus disease 2019 (COVID-19). JAMA Cardiol. 5, 819-824.

Intensive Care National Audit and Research Centre (ICNARC) (2020). Intensive Care National Audit \& Research Centre. London: ICNARC.

Islam, M. F., Cotler, J., and Jason, L. A. (2020). Post-viral fatigue and COVID-19: lessons from past epidemics. Fatigue Biomed. Health Behav. 8, 61-69.

Jamnick, N. A., Pettitt, R. W., Granata, C., Pyne, D. B., and Bishop, D. J. (2020). An examination and critique of current methods to determine exercise intensity. Sports Med. 50, 1729-1756. doi: 10.1007/s40279-020-01322-8

Jia, X., Yin, C., Lu, S., Chen, Y., Liu, Q., Bai, J., et al. (2020). Two things about COVID-19 might need attention. [Preprints]. doi: 10.20944/preprints202002. 0315.v1

Khaleghzadeh, H., Afzalpour, M. E., and Ahmadi, M. M. (2020). Effect of high intensity interval training along with Oligopin supplementation on some inflammatory indices and liver enzymes in obese male Wistar rats with nonalcoholic fatty liver disease. Obes. Med. 2020:17100177.

Khoramipour, K., Basereh, A., Hekmatikar, A. A., Castell, L., Ruhee, R. T., and Suzuki, K. (2021). Physical activity and nutrition guidelines to help with the fight against COVID-19. J. Sports Sci. 39, 101-107.

Kiel, R. J., Smith, F. E., Chason, J., Khatib, R., and Reyes, M. P. (1989). Coxsackievirus $\mathrm{B} 3$ myocarditis in $\mathrm{C} 3 \mathrm{H} / \mathrm{HeJ}$ mice: description of an inbred model and the effect of exercise on virulence. Eur. J. Epidemiol. 50, 1729-1756.

Kohut, M. L., Arntson, B. A., Lee, W., Rozeboom, K., Yoon, K. J., Cunnick, J. E., et al. (2004). Moderate exercise improves antibody response to influenza immunization in older adults. Vaccine 22, 2298-2306. doi: 10.1016/j.vaccine. 2003.11 .023
Kompaniyets, L., Goodman, A. B., Belay, B., Freedman, D. S., Sucosky, M. S., Lange, S. J., et al. (2021). Body mass index and risk for COVID-19-related hospitalization, intensive care unit admission, invasive mechanical ventilation, and death - United States, March-December 2020. MMWR Morb. Mortal Wkly. Rep. 70, 355-361. doi: 10.15585/mmwr.mm7010e4

Krüger, K., Mooren, F. C., and Pilat, C. (2016). The immunomodulatory effects of physical activity. Curr. Pharm. Des. 22, 3730-3748. doi: 10.2174/ 1381612822666160322145107

Laddu, D. R., Lavie, C. J., Phillips, S. A., and Arena, R. (2021). Physical activity for immunity protection: inoculating populations with healthy living medicine in preparation for the next pandemic. Prog. Cardiovasc. Dis. 64, 102-104.

Lancaster, G. I., Khan, Q., Drysdale, P., Wallace, F., Jeukendrup, A. E., Drayson, M. T., et al. (2005). The physiological regulation of toll-like receptor expression and function in humans. J. Physiol. 563(Pt 3), 945-955. doi: 10.1113/jphysiol. 2004.081224

Li, J. (2020). Rehabilitation management of patients with COVID-19: lessons learned from the first experience in China. Eur. J. Phys. Rehabil. Med. 56, 335-338. doi: 10.23736/S1973-9087.20.06292-9

Lu, R., Zhao, X., Li, J., Niu, P., Yang, B., Wu, H., et al. (2020). Genomic characterisation and epidemiology of 2019 novel coronavirus: implications for virus origins and receptor binding. Lancet 395, 565-574.

Luzi, L., and Radaelli, M. G. (2020). Influenza and obesity: its odd relationship and the lessons for COVID-19 pandemic. Acta Diabetol. 57, 759-764. doi: 10.1007/s00592-020-01522-8

MacIntosh, B. R., Murias Juan, M., Keir Daniel, A., and Weir Jamie, M. (2021). What is moderate to vigorous exercise intensity? Front. Physiol. 12:682233. doi: $10.3389 /$ fphys.2021.682233

Magalhães, D. M., Nunes-Silva, A., Rocha, G. C., Vaz, L. N., de Faria, M., Vieira, E., et al. (2020). Two protocols of aerobic exercise modulate the counter-regulatory axis of the renin-angiotensin system. Heliyon 6:e03208.

Mailing, L. J., Allen, J. M., Buford, T. W., Fields, C. J., and Woods, J. A. (2019). Exercise and the gut microbiome: a review of the evidence, Potential Mechanisms, and Implications for Human Health. Exerc. Sport Sci. Rev. 47, 75-85. doi: 10.1249/JES.0000000000000183

Maron, B. J., Haas, T. S., Ahluwalia, A., Murphy, C. J., and Garberich, R. F. (2016). Demographics and epidemiology of sudden deaths in young competitive athletes: from the United States National Registry. Am. J. Med. 129, $1170-1177$.

Matthews, C. E., Ockene, I. S., Freedson, P. S., Rosal, M. C., Merriam, P. A., and Hebert, J. R. (2002). Moderate to vigorous physical activity and risk of upper-respiratory tract infection. Med. Sci. Sports Exerc. 34, 1242-1248. doi: 10.1097/00005768-200208000-00003

McKinney, J., Connelly, K. A., Dorian, P., Fournier, A., Goodman, J. M., Grubic, N., et al. (2021). COVID-19-myocarditis and return to play: reflections and recommendations from a canadian working group. Can. J. Cardiol. 37, 11651174 .

Mehta, P., McAuley, D. F., Brown, M., Sanchez, E., Tattersall, R. S., and Manson, J. J. (2020). COVID-19: consider cytokine storm syndromes and immunosuppression. Lancet 395, 1033-1034.

Menter, T., Haslbauer, J. D., Nienhold, R., Savic, S., Hopfer, H., Deigendesch, N., et al. (2020). Postmortem examination of COVID-19 patients reveals diffuse alveolar damage with severe capillary congestion and variegated findings in lungs and other organs suggesting vascular dysfunction. Histopathology 77, 198-209. doi: 10.1111/his.14134

Moin, A. S. M., Al-Qaissi, A., Sathyapalan, T., Atkin, S. L., and Butler, A. E. (2020). Renin-angiotensin system overactivation in Type 2 diabetes: a risk for SARS-CoV-2 infection? Diabetes Care 43, e131-e133. doi: 10.2337/dc201115

Moreira, A., Delgado, L., Moreira, P., and Haahtela, T. (2009). Does exercise increase the risk of upper respiratory tract infections? Br. Med. Bull. 90, 111-131. doi: 10.1093/bmb/ldp010

Nieman, D. C. (1994). Exercise, infection, and immunity. Int. J. Sports Med. 15(Suppl. 3), S131-S141. doi: 10.1055/s-2007-1021128

Nieman, D. C., and Pedersen, B. K. (1999). Exercise and immune function. Sports Med. 27, 73-80. doi: 10.2165/00007256-199927020-00001

Nieman, D. C., and Wentz, L. M. (2019). The compelling link between physical activity and the body's defense system. J. Sport Health Sci. 8, 201-217. doi: 10.1016/j.jshs.2018.09.009 
Nieman, D. C., Henson, D. A., Austin, M. D., and Sha, W. (2011). Upper respiratory tract infection is reduced in physically fit and active adults. Br. J. Sports Med. 45, 987-992. doi: 10.1136/bjsm.2010.077875

Nobari, H., Fashi, M., Eskandari, A., Villafaina, S., Murillo-Garcia, Á, and PérezGómez, J. (2021b). Effect of COVID-19 on health-related quality of life in adolescents and children: a systematic review. Int. J. Environ. Res. Public Health 18:4563.

Nobari, H., Fashi, M., Eskandari, A., Pérez-Gómez, J., and Suzuki, K. (2021a). Potential improvement in rehabilitation quality of 2019 novel Coronavirus by isometric training system; is there "Muscle-Lung Cross-Talk"? Intern. J. Environ. Res. Public Health 18:6304. doi: 10.3390/ijerph18126304

Nunes-Silva, A., Rocha, G. C., Magalhaes, D. M., Vaz, L. N., Salviano de Faria, M. H., and Simoes, E. S. A. C. (2017). Physical exercise and ACE2-angiotensin(1-7)-mas receptor axis of the renin angiotensin system. Protein Pept. Lett. 24, 809-816. doi: 10.2174/0929866524666170728151401

Ocaranza, M. P., and Jalil, J. E. (2012). Protective role of the ACE2/Ang-(1-9) axis in cardiovascular remodeling. Int. J. Hypertens. 2012:594361. doi: 10.1155/2012/ 594361

Olkowicz, M., Chlopicki, S., and Smolenski, R. T. (2015). Perspectives for angiotensin profiling with liquid chromatography/mass spectrometry to evaluate ACE/ACE2 balance in endothelial dysfunction and vascular pathologies. Pharm. Rep. 67, 778-785. doi: 10.1016/j.pharep.2015.03.017

Pedersen, B. K., and Saltin, B. (2006). Evidence for prescribing exercise as therapy in chronic disease. Scand. J. Med. Sci. Sports 16, 3-63.

Peters, E. M., and Bateman, E. D. (1983). Ultramarathon running and upper respiratory tract infections. An epidemiological survey. S. Afr. Med. J. 64, 582-584.

Philippe, M., Gatterer, H., Burtscher, M., Weinberger, B., Keller, M., GrubeckLoebenstein, B., et al. (2019). Concentric and eccentric endurance exercise reverse hallmarks of T-Cell senescence in pre-diabetic subjects. Front. Physiol. 10:684. doi: 10.3389/fphys.2019.00684

Piercy, K. L., Troiano, R. P., Ballard, R. M., Carlson, S. A., Fulton, J. E., Galuska, D. A., et al. (2018). The physical activity guidelines for americans. JAMA 320, 2020-2028. doi: 10.1001/jama.2018.14854

Pinto, B. G. G., Oliveira, A. E. R., Singh, Y., Jimenez, L., Gonçalves, A. N. A., Ogava, R. L. T., et al. (2020). ACE2 expression is increased in the lungs of patients with comorbidities associated with severe COVID-19. J. Infect. Dis. 222, 556-563. doi: 10.1093/infdis/jiaa332

Piquet, V., Luczak, C., Seiler, F., Monaury, J., Martini, A., Ward, A. B., et al. (2021). Do Patients with COVID-19 benefit from rehabilitation? Functional outcomes of the First 100 patients in a COVID-19 rehabilitation unit. Arch. Phys. Med. Rehabil. 102, 1067-1074.

Prata, L. O., Rodrigues, C. R., Martins, J. M., Vasconcelos, P. C., Oliveira, F. M., Ferreira, A. J., et al. (2017). Original research: ACE2 activator associated with physical exercise potentiates the reduction of pulmonary fibrosis. Exp. Biol. Med. 242, 8-21. doi: 10.1177/1535370216665174

Quiroga, R., Nistal, E., Estébanez, B., Porras, D., Juárez-Fernández, M., MartínezFlórez, S., et al. (2020). Exercise training modulates the gut microbiota profile and impairs inflammatory signaling pathways in obese children. Exp. Mol. Med. 52, 1048-1061. doi: 10.1038/s12276-020-0459-0

Ragab, D., Salah Eldin, H., Taeimah, M., Khattab, R., and Salem, R. (2020). The COVID-19 cytokine storm: what we know so far. Front. Immunol. 11:1446. doi: 10.3389/fimmu.2020.01446

Rahmati-Ahmadabad, S., and Hosseini, F. (2020). Exercise against SARS-CoV-2 (COVID-19): does workout intensity matter? (A mini review of some indirect evidence related to obesity). Obes. Med. 19:100245. doi: 10.1016/j.obmed.2020. 100245

Reed, J. L., and Pipe, A. L. (2014). The talk test: a useful tool for prescribing and monitoring exercise intensity. Curr. Opin. Cardiol. 29, 475-480. doi: 10.1097/ HCO.0000000000000097

Reza, M. M., Subramaniyam, N., Sim, C. M., Ge, X., Sathiakumar, D., McFarlane, C., et al. (2017). Irisin is a pro-myogenic factor that induces skeletal muscle hypertrophy and rescues denervation-induced atrophy. Nat. Commun. 8, 1-17.

Rigat, B., Hubert, C., Alhenc-Gelas, F., Cambien, F., Corvol, P., and Soubrier, F. (1990). An insertion/deletion polymorphism in the angiotensin I-converting enzyme gene accounting for half the variance of serum enzyme levels. J. Clin. Invest. 86, 1343-1346. doi: 10.1172/JCI114844
Rothan, H. A., and Byrareddy, S. N. (2020). The epidemiology and pathogenesis of coronavirus disease (COVID-19) outbreak. J. Autoimmun. 109:102433.

Ruhee, R. T., and Suzuki, K. (2020). The integrative role of sulforaphane in preventing inflammation, oxidative stress and fatigue: a review of a potential protective phytochemical. Antioxidants 9:521. doi: 10.3390/antiox906 0521

Sallis, R., Young, D. R., Tartof, S. Y., Sallis, J. F., Sall, J., Li, Q., et al. (2021). Physical inactivity is associated with a higher risk for severe COVID-19 outcomes: a study in 48440 adult patients. Br. J. Sports Med. 55, 1099-1105.

Salman, D., Vishnubala, D., Le Feuvre, P., Beaney, T., Korgaonkar, J., Majeed, A., et al. (2021). Returning to physical activity after covid-19. BMJ 372:m4721. doi: 10.1136/bmj.m4721

Scherr, J., Wolfarth, B., Christle, J. W., Pressler, A., Wagenpfeil, S., and Halle, M. (2013). Associations between Borg's rating of perceived exertion and physiological measures of exercise intensity. Eur. J. Appl. Physiol. 113, 147-155. doi: 10.1007/s00421-012-2421-x

Shi, Y., Wang, Y., Shao, C., Huang, J., Gan, J., Huang, X., et al. (2020). COVID19 infection: the perspectives on immune responses. Cell Death Differ. 27, 1451-1454. doi: 10.1038/s41418-020-0530-3

Silva, S. D., Jara, Z. P., Peres, R., Lima, L. S., Scavone, C., Montezano, A. C., et al. (2017). Temporal changes in cardiac oxidative stress, inflammation and remodeling induced by exercise in hypertension: role for local angiotensin II reduction. PLoS One 12:0189535. doi: 10.1371/journal.pone.0189535

Silva, S. D., Zampieri, T. T., Ruggeri, A., Ceroni, A., Aragão, D. S., Fernandes, F. B., et al. (2015). Downregulation of the vascular renin-angiotensin system by aerobic training - focus on the balance between vasoconstrictor and vasodilator axes. Circ. J. 79, 1372-1380. doi: 10.1253/circj.CJ-14-1179

Simpson, R. J., Campbell, J. P., Gleeson, M., Krüger, K., Nieman, D. C., Pyne, D. B., et al. (2020). Can exercise affect immune function to increase susceptibility to infection? Exerc. Immunol. Rev. 26, 8-22.

Siripanthong, B., Nazarian, S., Muser, D., Deo, R., Santangeli, P., Khanji, M. Y., et al. (2020). Recognizing COVID-19-related myocarditis: the possible pathophysiology and proposed guideline for diagnosis and management. Heart Rhythm 17, 1463-1471. doi: 10.1016/j.hrthm.2020. 05.001

Slentz, C. A., Bateman, L. A., Willis, L. H., Shields, A. T., Tanner, C. J., Piner, L. W., et al. (2011). Effects of aerobic vs. resistance training on visceral and liver fat stores, liver enzymes, and insulin resistance by HOMA in overweight adults from STRRIDE AT/RT. Am. J. Physiol. Endocrinol. Metab. 301, 1033-1039.

Steensberg, A., Fischer, C. P., Keller, C., Møller, K., and Pedersen, B. K. (2003). IL-6 enhances plasma IL-1ra, IL-10, and cortisol in humans. Am. J. Physiol. Endocrinol. Metab. 285, E433-E437. doi: 10.1152/ajpendo.00074.2003

Suzuki, K. (2019). Chronic inflammation as an immunological abnormality and effectiveness of exercise. Biomolecules 9:223.

Suzuki, K., and Hayashida, H. (2021). Effect of exercise intensity on cell-mediated immunity. Sports 9:8.

Tikellis, C., and Thomas, M. C. (2012). Angiotensin-converting enzyme 2 (ACE2) is a key modulator of the renin angiotensin system in health and disease. Int. J. Pept. 2012:256294.

Tipnis, S. R., Hooper, N. M., Hyde, R., Karran, E., Christie, G., and Turner, A. J. (2000). A human homolog of angiotensin-converting enzyme. Cloning and functional expression as a captopril-insensitive carboxypeptidase. J. Biol. Chem. $275,33238-33243$.

Turner, J. E., Spielmann, G., Wadley, A. J., Aldred, S., Simpson, R. J., and Campbell, J. P. (2016). Exercise-induced B cell mobilisation: preliminary evidence for an influx of immature cells into the bloodstream. Physiol. Behav. 164(Pt A), 376-382. doi: 10.1016/j.physbeh.2016.06.023

Tyrankiewicz, U., Olkowicz, M., Berkowicz, P., Jablonska, M., Smolenski, R. T., Zoladz, J. A., et al. (2021). Physical activity and inhibition of ACE additively modulate ACE/ACE-2 balance in heart failure in mice. Front. Pharmacol. 12:682432. doi: 10.3389/fphar.2021.682432

Vaduganathan, M., Vardeny, O., Michel, T., McMurray, J. J. V., Pfeffer, M. A., and Solomon, S. D. (2020). Renin - angiotensin - aldosterone system inhibitors in patients with Covid-19. N. Engl. J. Med. 382, 1653-1659.

Valenzuela, P. L., Simpson, R. J., Castillo-García, A., and Lucia, A. (2021). Physical activity: a coadjuvant treatment to COVID-19 vaccination? Brain Behav. Immun. 94, 1-3. doi: 10.1016/j.bbi.2021.03.003 
Vargas-Mendoza, N., Morales-González, Á, Madrigal-Santillán, E. O., MadrigalBujaidar, E., Álvarez-González, I., García-Melo, L. F., et al. (2019). Antioxidant and adaptative response mediated by Nrf2 during physical exercise. Antioxidants 8:196.

Vellers, H. L., Kleeberger, S. R., and Lightfoot, J. T. (2018). Inter-individual variation in adaptations to endurance and resistance exercise training: genetic approaches towards understanding a complex phenotype. Mamm. Genome 1:2, 48-62. doi: 10.1007/s00335-017-9732-5

Verhein, K. C., Vellers, H. L., and Kleeberger, S. R. (2018). Inter-individual variation in health and disease associated with pulmonary infectious agents. Mamm. Genome 29, 38-47. doi: 10.1007/s00335-018-9733-z

Viveiros, A., Rasmuson, J., Vu, J., Mulvagh, S. L., Yip, C. Y. Y., Norris, C. M., et al. (2021). Sex differences in COVID-19: candidate pathways, genetics of ACE2, and sex hormones. Am. J. Physiol. Heart Circ. Physiol. 320, H296-H304.

Walsh, N. P. (2018). Recommendations to maintain immune health in athletes. Eur. J. Sport Sci. 18, 820-831. doi: 10.1080/17461391.2018.144 9895

Walsh, N. P., and Oliver, S. J. (2016). Exercise, immune function and respiratory infection: an update on the influence of training and environmental stress. Immunol. Cell Biol. 94, 132-139.

Walsh, N. P., Gleeson, M., Shephard, R. J., Gleeson, M., Woods, J. A., Bishop, N. C., et al. (2011). Position statement. Part one: immune function and exercise. Exerc. Immunol. Rev. 17, 6-63.

Wang, H., Sun, X., VonCannon, J. L., Kon, N. D., Ferarrio, C. M., and Groban, L. (2021). Estrogen receptors are linked to angiotensin-converting enzyme 2 (ACE2), ADAM metallopeptidase domain 17 (ADAM-17), and transmembrane protease serine 2 (TMPRSS2) expression in the human atrium: insights into COVID-19. Hypertens. Res. 44, 882-884. doi: 10.1038/s41440-02100626-0

Wang, M., Baker, J. S., Quan, W., Shen, S., Fekete, G., and Gu, Y. (2020). A preventive role of exercise across the coronavirus 2 (SARS-CoV-2) pandemic. Front. Physiol. 11:572718. doi: 10.3389/fphys.2020.572718

Wang, P., Li, C. G., Qi, Z., Cui, D., and Ding, S. (2016). Acute exercise stress promotes Ref1/Nrf2 signalling and increases mitochondrial antioxidant activity in skeletal muscle. Exp. Physiol. 101, 410-420. doi: 10.1113/EP085493

Warburton, D. E. R., Katzmarzyk, P. T., Rhodes, R. E., and Shephard, R. J. (2007). Evidence-informed physical activity guidelines for Canadian adults. Can. J. Public Health 98(Suppl. 2), S16-S68. doi: 10.1139/H07-123

Weinhold, M., Shimabukuro-Vornhagen, A., Franke, A., Theurich, S., Wahl, P., Hallek, M., et al. (2016). Physical exercise modulates the homeostasis of human regulatory T cells. J. Allergy Clin. Immunol. 137, 1607-1610.e8. doi: 10.1016/j. jaci.2015.10.035

Whitehead, N., Gill, J. F., Brink, M., and Handschin, C. (2018). Moderate modulation of cardiac PGC- $1 \alpha$ expression partially affects age-associated transcriptional remodeling of the heart. Front. Physiol. 9:242. doi: 10.3389/ fphys.2018.00242

Wiertsema, S. P., van Bergenhenegouwen, J., Garssen, J., and Knippels, L. (2021). The interplay between the gut microbiome and the immune system in the context of infectious diseases throughout life and the role of nutrition in optimizing treatment strategies. Nutrients 13:886. doi: 10.3390/nu13030886
Wong, C. M., Lai, H. K., Ou, C. Q., Ho, S. Y., Chan, K. P., Thach, T. Q., et al. (2008). Is exercise protective against influenza-associated mortality? PLoS One 3:e2108. doi: 10.1371 /journal.pone.0002108

World Health Organization (WHO) (2018). Global Action Plan on Physical Activity 2018-2030: More Active People for a Healthier World. Geneva: World Health Organization.

Yan, Z., and Spaulding, H. R. (2020). Extracellular superoxide dismutase, a molecular transducer of health benefits of exercise. Redox Biol. 32:101508.

Zbinden-Foncea, H., Francaux, M., Deldicque, L., and Hawley, J. A. (2020). Does high cardiorespiratory fitness confer some protection against pro-inflammatory responses after infection by SARS-CoV-2? Obes. Silver Spring Md. 28, 13781381.

Zeng, J. H., Liu, Y. X., Yuan, J., Wang, F. X., Wu, W. B., Li, J. X., et al. (2020). First case of COVID-19 complicated with fulminant myocarditis: a case report and insights. Infection 48, 773-777. doi: 10.1007/s15010-020-01424-5

Zhang, H., Penninger, J. M., Li, Y., Zhong, N., and Slutsky, A. S. (2020). Angiotensin-converting enzyme 2 (ACE2) as a SARS-CoV-2 receptor: molecular mechanisms and potential therapeutic target. Intens. Care Med. 46, 586-590.

Zhang, J., Dong, J., Martin, M., He, M., Gongol, B., Marin, T. L., et al. (2018). AMPactivated protein kinase phosphorylation of angiotensin-converting enzyme 2 in endothelium mitigates pulmonary hypertension. Am. J. Resp. Crit. Care Med. 198, 509-520. doi: 10.1164/rccm.201712-2570OC

Zhou, X., and Ye, Q. (2021). Cellular immune response to COVID-19 and potential immune modulators. Front. Immunol. 12:646333. doi: 10.3389/fimmu.2021. 646333

Zhu, L., She, Z. G., Cheng, X., Qin, J. J., Zhang, X. J., Cai, J., et al. (2020). Association of blood glucose control and outcomes in patients with COVID-19 and Preexisting Type 2 diabetes. Cell Metab. 31, 1068-1077.e3. doi: 10.1016/j.cmet. 2020.04.021

Zhu, W. (2020). Should, and how can, exercise be done during a coronavirus outbreak? An interview with Dr. Jeffrey A. Woods. J. Sport Health Sci. 9, 105-107. doi: 10.1016/j.jshs.2020.01.005

Conflict of Interest: The authors declare that the research was conducted in the absence of any commercial or financial relationships that could be construed as a potential conflict of interest.

Publisher's Note: All claims expressed in this article are solely those of the authors and do not necessarily represent those of their affiliated organizations, or those of the publisher, the editors and the reviewers. Any product that may be evaluated in this article, or claim that may be made by its manufacturer, is not guaranteed or endorsed by the publisher.

Copyright (C) 2021 Arazi, Falahati and Suzuki. This is an open-access article distributed under the terms of the Creative Commons Attribution License (CC BY). The use, distribution or reproduction in other forums is permitted, provided the original author(s) and the copyright owner(s) are credited and that the original publication in this journal is cited, in accordance with accepted academic practice. No use, distribution or reproduction is permitted which does not comply with these terms. 